\title{
Vita activa y lex naturae en Cromacio de Aquilea: el caso del Sermo III*
}

\author{
(4) Ferico Conti \\ Pontificium Institutum Altioris Latinitatis, Università Pontificia Salesiana, \\ Italia \\ ORCID: 0000-0002-8120-2637
}

Recibido: 27 de febrero de 2021, aceptado: 23 de marzo de 2021

\begin{abstract}
Resumen
Los Sermones de Cromacio de Aquilea nos ofrecen evidencia directa de su experiencia episcopal y literaria, que se divide entre la exégesis más destacada y el objetivo pastoral. La simplicidad estructural y lingüística, y la referencia a algunos autores contemporáneos, características de la tercera de estas composiciones homiléticas, nos ofrecen la oportunidad para analizar los propósitos más íntimos y prácticos de este texto. De hecho, la estrecha relación con su audiencia y el intento de guiarla por el justo camino cristiano son los evidentes protagonistas en todo el discurrir del sermón. Sin embargo, al mismo tiempo se observa también la exégesis escritural de Cromacio y su profundización doctrinal: el Obispo trata de ofrecer un pequeño pero útil bagaje para el camino de quien lo escucha, en una poderosa valorización de la acción humana. La vita activa que se suma a la lexnaturae inherente al alma humana constituye, de hecho, el tema más evidente de la homilía íntegra, que expone el de Aquilea sobre todo con el objetivo de fortalecer la unidad y la identidad de quienes escuchan cuando enfrentan presiones externas. La referencia escritural es fuerte y está presente en todo el sermón: el pasaje, seguramente leído justo antes de la exposición, se expone casi en su totalidad a los fieles, para fijarlo mejor en la memoria de aquellos que asisten a la lectura.
\end{abstract}

PALABRAS CLAVE: CROMACIO, SERMONES, ACCIÓN, PELAGIANISMO, IDENTIDAD.

\section{Vita activa and lex naturae in Chromatius of Aquileia: the case of Sermo III}

\begin{abstract}
The Sermones of Chromatius of Aquileia offer us direct evidence of his episcopal and literary experience, divided between the most marked exegesis and the pastoral


objective. The structural and linguistic simplicity and the reference to a few contemporary authors, characteristics of the third of these homiletic compositions, offer us the opportunity to analyse the most intimate and practical purposes of this text. The close relationship with the audience, in fact, and the intent to guide them on a right Christian path are evident protagonists in the flow of the entire sermon. At the same time, however, the scriptural exegesis of Chromatius and his doctrinal study run: the Bishop tries to offer a small baggage useful to the path of those who listen to him, in a strong enhancement of human action. The vita activa adhering to the lex naturae inherent in the human soul constitutes, in fact, the most evident theme of the entire homily, expounded by the Aquileian above all with the aim of strengthening the unity and the identity of the listeners in the face of external pressures. Above all, the scriptural reference is strong, present throughout the Sermo: the passage, certainly read just before the exposition, is almost entirely reported, and exposed to the faithful, so as to make it more fixed in the memory of those who attend.

KEYWORDS: CHROMATIUS, SERMONES, ACTION, PELAGIANISM, IDENTITY

\section{Introducción}

De la obra completa de Cromacio de Aquilea, los Sermones pueden considerarse un espejo fiel de su actividad episcopal, en tensión entre la ocupación pastoral y un impulso exegético más profundo. Este rasgo característico es propio de la parábola del Aquilense, reconocible ya sea en el Tractatus como en los Sermones: obispo y exégeta, las dos almas corren en paralelo en las palabras, encontrándose en la finalidad de su discurso. Particularmente, la tercera de estas composiciones homiléticas presenta tales notas características de la predicación y del pensamiento de Cromacio. En efecto, allí se encuentran los dos impulsos que animan las acciones del obispo y su predicación. Sin embargo, del Sermo III emerge una visión particular de la vita activa, conectada a una lex naturae inherente al alma humana, que Cromacio expone a sus oyentes partiendo de la referencia escritural, en este caso, de Hch 10: 1-23. En la lectura del Aquilense, el actuar aparece relacionado con la gracia -don recibido, respecto del cual debe ser conmensurado- y con la vida a la que se aspira, la celestial. Después de una descripción sumaria del sermón en cuestión atendiendo a su estructura, su exégesis y una breve contextualización, el objetivo del presente trabajo será el análisis de estos aspectos particulares del sermón que, por extensión, podría potencialmente abarcar la totalidad de la obra cromaciana. El estudio en cuestión consistirá en dos aspectos: en primer lugar, el análisis de lo que surge del sermón mismo, esto es, las características de esta vita activa que propone Cromacio y la finalidad de su teorización. En segundo lugar, esta última finalidad será relacionada con el estilo y las fuentes del obispo aquilense, con el objetivo de comprender de una mejor manera sus intenciones. La composición del resto encuentra sentido en la unión armoniosa de estos tres aspectos: exegético, pastoral y filosófico. Así, un análisis del sermón puede ayudar a iluminar tales características y asistir al encuadre histórico y literario de Cromacio de Aquilea, obispo en el sentido más amplio del término.

\section{Sermo III: contexto y estructura}

El tercero de los Sermones de Cromacio de Aquilea ${ }^{1}$ puede ser datado, al igual que gran parte de los otros, solo de manera aproximada, sobre todo a través de referencias internas en la propia obra del autor (Banterle y Lemarié, 1989: 9-13; Trettel, 1984). De esta manera, los Tractatus in Matthaeum pueden considerarse posteriores a los Sermones 
y, específicamente, se los puede encuadrar en el último tramo del episcopado y de la vida del Santo, esto es, entre el 400 y el $407 .{ }^{2}$ Es más, los sesenta y un tratados hacen referencia constante a la obra homilética anterior, muchas veces permitiéndose citas cuasi literales que presentan una reelaboración tanto formal como estructural (Cerno, 2015:9). Es natural, por tanto, considerar a los Sermones anteriores a este trabajo como un tipo más sistemático y de una finalidad un tanto más diversa, por lo que se los puede situar entre el inicio de la carrera eclesiástica de Cromacio y finales del 400, hipotético inicio de la escritura del Tractatus. ${ }^{3}$

En lo que respecta específicamente al Sermo III, no tenemos modo de precisar la datación de su composición, pues no han subsistido elementos internos al texto que nos permitan trazar referencias sea con alguna otra obra que ya tenga una datación establecida de manera certera, sea con eventos históricos documentados y documentables. Con todo, desde el contenido del texto recibimos indicaciones sobre el período del año litúrgico, durante el cual la exposición del sermón debe haber tenido lugar. El Obispo hace referencia, de manera incesante, a los ayunos y a las limosnas prescriptas a los fieles que, con escaso sentido cristiano, encuentran excusas de las más banales para evitar la norma. ${ }^{4}$ Sobre esta base, presumiblemente, pero también en virtud del pasaje neotestamentario abordado, podemos afirmar que la ocasión para la escritura y exposición fue el período pascual, en el que tales prescripciones representan la norma (Banterle y Lemarié, 1989: 33). Con similar presunción de verosimilitud es lícito afirmar que la exposición tuvo efectivamente lugar en la ciudad de Aquilea, donde Cromacio fue obispo por largo tiempo..$^{5}$ A fin de cuentas, los Sermones son el espejo de una actividad pastoral que duró casi medio siglo, si bien al Arzobispo no le faltó ocasión para realizar viajes. En efecto, participó en numerosos sínodos y concilios locales, haciéndose partícipe de la vida teológica, social y cultural de su tiempo, forjando contacto también con personajes destacados, tales como Ambrosio de Milán, Jerónimo y Rufino. Pero si esta actividad se confirma a través de pruebas documentales y escritos contemporáneos a él, entonces no tenemos en verdad modo alguno de colocar algunas de sus obras por fuera del círculo restringido de Aquilea. Ciertamente, Cromacio permanece indisolublemente ligado a la ciudad friulana: allí nació, vivió, desarrolló principalmente su trabajo y murió (Sotinel, 2005; Bratoz, 1999).

El Sermo III, así como el resto de los textos contenidos en el conjunto, debe haber sido expuesto frente a un auditorio de su diócesis. ${ }^{6}$ La estrecha confianza que une al orador con quienes escuchan nos permite llegar a la misma conclusión. En efecto, quien habla conoce muy bien a quien escucha, observa sus comportamientos en la cotidianidad y en la frecuentación asidua de la Iglesia conoce los pensamientos que ocupan su alma, como es posible notar en Sermo III.1-2. Por tanto, los destinatarios no pueden ser más que los diocesanos de Aquilea que asisten frecuentemente a las oraciones del Obispo. La voluntad de Cromacio busca apartar a los fieles cercanos a él de comportamientos y conductas que son contrarios a la actitud cristiana, y

2 El 407 es la fecha de muerte históricamente aceptada. Sin embargo, fue demostrada la presencia del Obispo en el concilio de Dióspolis del 415, hecho que trasladará su fecha de muerte más adelante. Beatrice, 2014: 449-452.

3 Esto es lo que surge también desde Benterle y Lemarié, 1989: 9-11; Truzzi, 1981.

${ }_{4}$ Cf. Sermo III.1-2, pero en la totalidad del sermón los términos ieiunus, -i, y eleemosyna, -ae y sus respectivos derivados lo recorren de manera constante. El intento es claro desde el primer momento: la repetición facilita el aprendizaje: en la visión de Cromacio de un obispo como centro de la diócesis, esta forma de enseñanza-corrección es el fin primario de la acción pastoral.

5 Cf. Beatrice, 2014; Sotinel, 2011. Para una síntesis de la relación entre Cromacio obispo y la ciudad de Aquilea véase McEachnie, 2017.

6 Ya en el exordio del sermón parece demostrar de manera inequívoca cómo esto se sigue inmediatamente luego de la lectura del pasaje neotestamentario. En efecto, leemos en el comienzo de la oración en cuestión: “Cornelius centurio quantam devotionem circa Deum habuerit, audivit dilectio vestra". Pero las referencias de la efectiva lectura del pasaje no se agotan en el exordio del retórico, sino que también se continúan de una manera más ligera e indirecta por toda la duración del sermón. 
aprovecha la ocasión de la historia del centurión Cornelio para evidenciar lo que a sus ojos no es adecuado. Los hermanos criticados por Cromacio no respetan las prescripciones del ayuno, encontrando razones absurdas para evitar la penitencia, no practican la limosna correctamente y se entrometen en asuntos terrenales durante la celebración de la misa. A esto contrapone, precisamente, el estilo de vida del centurión pagano Cornelio, cristiano incluso antes de conocer a Cristo y su predicación (Hch 10). Los destinatarios representan también, contemporáneamente, a los adversarios del arzobispo al momento de la exposición del sermón: no adversarios a los que hay que excluir o evitar, sino hermanos a los que hay que corregir en las actividades cotidianas. En efecto, es propiamente esta la intención de todo el contenido pastoral del tercero de los 43 sermones de Cromacio de Aquilea: corregir a los fieles que erran en su camino cristiano, hacerlos volver a la vía signada por Cristo a través del ejemplo neotestamentario, cuyo análisis propone en esta breve homilía (Cerno, 2019).

De esta manera, el sermón sigue los pasos de la lectura de un pasaje de los Hechos de los Apóstoles, precisamente el 10: 1-23. El episodio allí narrado es el que refiere al centurión Cornelio quien, como se dijo, era "religioso y temeroso de Dios" (Hch. 10: 2), a pesar de ser ignorante de la predicación de Cristo y, por tanto, todavía formalmente pagano. Dedicado a la limosna, al ayuno y, sobre todo, a la plegaria, recibe en una visita a un ángel del Señor, quien le advierte que sus plegarias han llegado hasta el Altísimo y han sido escuchadas. ${ }^{7}$ La aparición incentiva verbalmente al centurión de la Legio Italica ${ }^{8}$ para enviar hombres a Jaffa para encontrar a Pedro, que se estaba quedando allí. El breve pasaje, repetido casi en su totalidad en el sermón por medio de citas, prosigue y concluye con la vívida visión de Pedro durante la plegaria a la sexta hora o al mediodía. Este, que había subido a la terraza para rezar, ve un gran lienzo blanco descender desde el cielo, atado por cuatro puntas y con toda especie de animales, desde reptiles hasta pájaros, en su interior. Una voz, aquella de Dios, ordena al Apóstol: "surge et immola et manduca". Frente a la reticencia de Pedro a asesinar y comerse las creaturas repugnantes, el Señor responde: "quae Deus mundavit, tu ne commune dixeris". Realizado el ascenso y el descenso tres veces, el lienzo blanco asciende nuevamente al cielo, desapareciendo definitivamente (Sermo III.4; cf. Hch 10: 15). ${ }^{9}$

Desde un punto de vista estructural, podemos notar, incluso con bastante claridad, cómo el sermón tiene una estructura tripartita: ${ }^{10}$ el comienzo se dedica a la realidad contingente, comparando el episodio bíblico con los errores y los pecados de los fieles; una segunda parte se centra en el episodio de Cornelio, donde se propone una interpretación exegética de índole tipológica, ${ }^{11}$ una tercera parte, finalmente, se dedica a una exégesis alegórica de la visión de Pedro, con interesantes notas teológicas.

Como afirmamos, el Señor escuchó las plegarias del centurión, considerando su estilo de vida y sus acciones como signo de piedad: practicaba ayuno y limosna y se prestaba

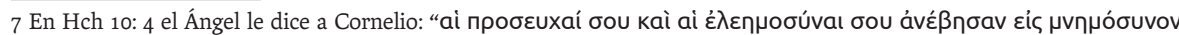

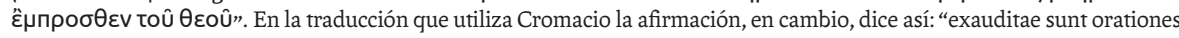
tuae, et eleemosynae tuae ascenderunt in memoriam coram Deo". El breve giro en las palabras reviste en el Sermón un rol de primer plano, porque el autor tiende a repetirlo de manera más que continua, con el objetivo de fijarlo en la mente de sus oyentes. Esto, como tendremos ocasión de ver, es uno de los rasgos típicos de este Sermo.

8 La Legio fue formada por Nerón en el 66-67 y permanece activa hacia el siglo V y, como testimonia Flavio Josefo en Bell. Iud. VIII.4.3, estuvo activa en Galilea hasta el fin del siglo I.

9 El pasaje ya había sido explicado por Orígenes. Cromacio se limita a utilizar la interpretación anterior.

10 La simplicidad de la estructura recalca en pleno la simplicidad y la fluidez del estilo; pensado para un público no culto, el sermón apunta a la claridad explicativa más que al ornamento retórico.

11 En el Sermo III.3, de manera explícita, Cromacio declara que emprende una exégesis de tipo tipológico, al afirmar que: "Quem tamen Cornelium iam Dominus in evangelio sancto Petro typice demonstraverat, ecc...". Sobre la particularidad exegética del cristianismo occidental véase Simonetti, 2012; Crouzel, 1964: 161-170. Respecto a la exégesis cromaciana en lo específico, se sigue a Trettel, $1981 \mathrm{a}$.
} 
a la plegaria antes que a cualquier otra ocupación terrena. Y es aquí donde Cromacio, obispo y pastor, nota una distorsión entre el proto-cristianismo modelo y su auditorio, al menos en la gran mayoría: los fieles de su tiempo evitan esas pocas ocupaciones listadas con excusas banales y, al actuar así, se alejan del mensaje evangélico. Pero si se quiere, como afirma el Obispo, que las plegarias sean contestadas, entonces estas deben ir acompañadas por un estilo de vida cristiano: las acciones deben ser inderogablemente conformes a los preceptos. Si un pagano como Cornelio tuvo la beatitud para recibir la gracia sin haber conocido a Cristo, ¿por qué los fieles de su diócesis, que, por el contrario, han tenido la gracia de conocerlo, no están en condiciones de recibir la misma beatitud? (Trettel, 1981b). Para Cromacio, la diferencia es sustancial y clara: reside plenamente en el actuar. El que presenta el Aquilense es un claro ejemplo de exégesis tropológica, en la cual el episodio de las Escrituras se toma como tal, extrayendo de él lecciones para la vida cotidiana: en este caso, un $\kappa \tau \tilde{\eta} \mu \alpha \dot{\varepsilon} \varsigma$ aísí para el camino cristiano.

La segunda y tercera parte del sermón representan el verdadero núcleo de la composición; en ellas el espíritu del obispo y del exégeta se expresan al unísono: una sola voz que transmite su mensaje más denso y significativo. Como afirmamos, el sermón es extremadamente lineal en tanto sigue directamente el orden escritural al efectuar la exégesis del texto casi palabra por palabra. De hecho, en primer lugar, se trata por segunda vez el episodio ocurrido a Cornelio, pero ahora aplicándole una interpretación tipológica (Trettel, 1981: 25 ss.). Cromacio rastrea la prefiguración del acontecimiento en cuestión no en el Antiguo Testamento, sino en el Nuevo, específicamente, en Mt 17:26. El primer pez que hubiera mordido el anzuelo de Pedro representaría a Cornelio in toto: el primero de los paganos en acercarse al anzuelo de la predicación, al señuelo de la salvación representada por el mensaje y predicación de Cristo, pez de un mar infinito, símbolo de las personas. En la historia evangélica, en la boca del pescado se habría encontrado un peso de balanza, que para Cromacio representa simbólicamente una expresión de justicia. Y es aquí donde toma forma completa la prefiguración. El pez, el primer fiel pescado, tenía ya en sí la "iustitiam Dei naturali lege" (Sermo III.4), con sus comportamientos y actitudes ya servía al mensaje evangélico: sin conocerlo, lo llevaba a cabo. Para el Aquilense, la enseñanza de Cristo es, en efecto, la más conforme a la ley natural y Cornelio, con tan solo adoptar un vivir piadoso, se conformó a esta enseñanza.

Una exégesis más clara y evidentemente alegórica se realiza en la tercera y última sección del sermón, la cual se dedica a la visión de Pedro. ${ }^{12}$ El mismo Cromacio en Sermo III.5 afirma que "mysticus et spiritalis in gestis huiusmodi sensus est". El adjetivo mysticus y más raramente el término spiritalis son utilizados a menudo en la composición homilética del Obispo para indicar el sentido encontrado a través de la alegoría: el mismo significado encuentran en este sermón. ${ }^{13}$ Pilar de la interpretación exegética es la centralidad de la Iglesia, única vía para la salvación, don de Dios a los hombres. ${ }^{14}$ Cromacio analiza cada elemento de la aparición, dándole un rol al interior del cuadro de conjunto y extrapolando un mensaje de validez doctrinal útil para su auditorio. Pedro se mueve del terreno de la casa a un lugar más elevado, representado por la terraza. En la interpretación del Aquilense, esto simboliza la necesidad del Apóstol no tanto de bienes terrenales, cuanto de bienes superiores: elevándose físicamente, se eleva espiritualmente. ${ }^{15}$ Del mismo modo, Pedro comienza

12 El sentido alegórico y espiritual es investigado por Cromacio pero en clave comunitaria, para mejorar la vida de su Iglesia, en la óptica ya mencionada de un obispo que tiene como primera intención la salvación de sus fieles. Cf. Trettel, 1974: 55-81.

13 Véase también Tract. in Matth. 44: 4: "Haec ipsa Domini gesta spiritalium in se rerum continent rationem".

14 Sobre la centralidad de la Iglesia en Cromacio, véase Todde, 1982.

15 Sermo III.5: "Superiora plane, quia fide sua superna quaerebat". 
a tener hambre durante la plegaria de la hora sexta un hambre de bienes divinos: en la exégesis cromaciana, no podía tratarse de un horario diferente del día, sino de aquel en el cual fue crucificado el Salvador y se cumplió la obra de redención y salvación del hombre. ${ }^{16}$

Asimismo, alegóricamente el lienzo blanco que desciende del cielo representa a la Iglesia, libre y pura de todo pecado, don de Dios a los hombres y apoyada en la enseñanza cuadripartita evangélica: en efecto, cuatro son los nudos que la mantienen unida. Aquí, la variedad de los animales contenida simboliza la apertura de la nueva creencia en Cristo: cualquiera es bienvenido, sin distinción de origen, etnia, censo o clase social. Y, como afirma con "quae Deus mundavit, tu ne commune dixeris" (Sermo III.4), quien entra a ser parte de la Iglesia del Señor queda purificado de todo lo que era en el pasado, tal como los animales con los cuales Pedro es invitado a prepararse una comida. La purificación adviene a través de la muerte, un asesinato de la propia vida pasada, para así poder renacer en Cristo a través del bautismo. "Surge et immola et manduca" (Sermo III.4): se llama al Apóstol a convertirse con su divinum gladium, con la palabra del Señor, asesinando y haciendo renacer a los nuevos convertidos. El sacramento del bautismo se descubre también en el movimiento del lienzo que asciende y vuelve a descender por tres veces consecutivas antes de subir definitivamente. Esto es, obviamente, un llamado a la Trinidad -también en las palabras de Cromacio- pero es, sobre todo, una referencia trinitaria en el ritual bautismal: quien comienza a ser parte de la Iglesia abandona el sí mismo del pasado y es bendecido tres veces: en el nombre del Padre, del Hijo y del Espíritu Santo. Purificado e inmolado, el individuo se libera del pecado y, puro, ingresa en la comunidad cristiana en el nombre de la Trinidad.

\section{La exégesis cromaciana entre la vita activa y la lex naturae}

El interés primario de Cromacio de Aquilea es, indudablemente, el pastoral: en tanto obispo, los objetivos primarios de su expresión resultan ser el mejoramiento y el progreso de quienes lo escuchan, la corrección de sus errores y, en última instancia, la salvación de su alma. ${ }^{17}$ En la predicación del Aquilense es central la función del obispo, ojo que "sine dubio omne ecclesiae corpus illuminat" (Sermo VI.2). Es por ello que la lectura está primariamente relacionada con la cotidianidad, y el sentido tropológico de la Escritura asume un rol fundamental. Así, la intención es claramente alcanzar la máxima comprensión, brindar el mayor apoyo posible a la propia diócesis.

A la atención pastoral, sin embargo, se une de manera indisociable la doctrinal: Cromacio intenta durante todo el sermón brindar a quien lo escucha certezas importantes en las que el fiel pueda encontrarse. ${ }^{18}$ No se trata de una profundización doctrinal realizada de manera abierta y explícita, sino más bien de pequeños vestigios de reflexiones que confluyen en el texto. El aspecto doctrinal no se profundiza porque para el autor los principios fundamentales constituyen una certeza inamovible, y así su estudio en profundidad tiene poco sentido. En cambio, resulta interesante notar cómo en la oración en cuestión no basta solamente la fe para recibir la gracia divina y alcanzar la salvación del alma, sino que el pilar es la propia actitud, el comportamiento cotidiano. El actuar en todos sus significados requiere prestar atención constantemente, de monitorear y modular en clave escatológica.

16 Sermo III.6: "nec alio sane tempore esusire Petrus debuit, ut in hora Sexta. Sexta enim hora Dominus crucifixus est".

17 Es evidente cómo en el ideal cromaciano solamente en la Iglesia, representada por el obispo, el hombre puede encontrar su salvación. El dictado a seguir es siempre el de las Escrituras y el ejemplo al que siempre se refieren los mártires. Cf. Lemarié, 1969 
Con todo, en una parte del texto el autor incurre, de una manera muy ligera, en una forma mitigada de pelagianismo contemporáneo. Habíamos señalado cómo, en el desarrollo de su discurso, Cromacio da una notable importancia al modo en que los fieles de su diócesis viven su vida de cristianos, cómo intenta durante todo el sermón corregir los errores comunes entre sus hermanos. Sin embargo, casi al cierre afirma: "purificari a peccatis non possumus, nisi per Trinitatis mysterium" (Sermo III.8). La heterodoxia podría parecer clara y la disminución del actuar humano, evidente, pero esto colisionaría con lo que se expuso más arriba. En efecto, si observamos mejor, podemos notar cómo un poco antes, en el mismo parágrafo, vuelve a enfatizar la función de la acción individual: "in conspectu eius vivere et conversari debemus, ut in adventu gloriae eius, non cum immundis et impiis poenas, sed cum sanctis et electis eius promissa regni caelestis et remunerationem vitae perpetuae consequamur" (Sermo III.8). Así, resulta claro cómo para Cromacio los dos aspectos son imprescindibles para la salvación humana, cómo no basta con la sola fe o con el solo actuar para conseguir la gracia, sino que ambos se entrelazan con fuerza. ${ }^{19}$ Pero hay más: el actuar debe ser proporcional a la misericordia recibida, debe, pues, ser irreprensible para poder convertirse en garante para la salvación. En un período de fuertes discusiones respecto a la Trinidad, resulta también interesante notar cómo en Cromacio la función del Espíritu Santo es clara y no sufre ninguna disminución, como demostraron Trettel (1983: 93-111) y Corgnali (1979): en este caso, el punto de apoyo de la Escritura es garantía de ortodoxia, en plena línea con las reflexiones de la teología propia de su tiempo.

De todos modos, Cromacio sigue claramente desarrollando la doctrina de la acción y un cierto tipo de teología del mérito, que históricamente identifica en el destino del centurión Cornelio un ejemplo de reconocimiento conferido por su respeto a la ley natural (Beatrice, 2014: 455). De hecho, el mismo autor afirma que quiere impulsar a quienes lo escuchan al compromiso, específicamente el de orientación cristiana (Sermo XXXII.4). Sin embargo, el intento del orador no es concebible sin evidenciar las relaciones con la gracia divina. Esta se recibe con el bautismo y acompaña al individuo en el curso de su vida, como es posible deducir de muchos pasajes del Aquilense (Sermones II.8; III.4; X.4; XIV.2; XIX.2). Si la fe es un don recibido a través de la gracia, el actuar debe estar relacionado con ella. La acción encuentra sentido en el intento de mantener inalterado el don recibido: es una fe viva, activa, que se mantiene en movimiento en la cotidianidad, devotio en el sentido más amplio del término. Por esta razón, el binomio fides-devotio que impregna la totalidad de la obra homilética del Obispo genera una acción pastoral que busca estimular la puesta en marcha por parte de los fieles de la asociación que acaba de exponer. La palabra de Dios, en tanto "esca animae y cibum fidei" (Sermo XII.6), nutre la fe y la corrobora. Así, Cromacio, con el recurso del pasaje elegido, insta al auditorio a la acción: una acción inspirada en la Escritura que permite al fiel conservar aquella gracia recibida en el acto del bautismo. De esta manera, la contraposición nítida en el Sermo III es aquella que se da entre la vita superna, la espiritual, y la vita terrena, preparatoria para la primera. En su despliegue signado por el actuar, la vida debe siempre estar relacionada con la espiritualidad, y la acción debe tener la misma inspiración. Superna no es sola la vida ultramundana, sino que puede y debe serlo también la vita terrena. Y esto solo puede acaecer mediante un actuar justo que, como dijimos, puede alcanzarse solamente mediante el ejemplo de la Escritura y la revelación divina.

La relación con el pelagianismo, por tanto, es ilusoria: el actuar toma relevancia solamente en relación con la gracia y, a la inversa, con la acción del Espíritu Santo. Si bien

19 Cf. Noce, 2011. Resulta claro cómo Cromacio anticipa la determinación antipelagiana propuesta por Agustín, considerando la fe y la gracia útiles solo si se dan en comunión. A este propósito, se revela importante recordar la presencia del Obispo de Aquilea en el sínodo de Dióspolis, destinado precisamente a frenar la difusión de la doctrina de Pelagio. Cf. Beatrice, 2014. 
en menor medida que las otras personas de la Trinidad, este último es valorizado y considerado medio indispensable para alcanzar la salvación (Sermo XVIII). Además, todo lo escrito en el pasaje de la Escritura -y en los dos Testamentos en generalresponde plenamente a la ley natural, ínsita en el alma humana. ${ }^{20}$ Por esta razón, en las palabras del Obispo, erra quien se separa de ella: efectivamente, va en contra de la misma naturaleza humana, volviéndose semejante a aquellos animales ofrecidos a Pedro y purificados por la revelación de Cristo. En líneas generales, el ser humano ha obtenido una plena realización de sí mismo en Cristo, que ha revelado aquella ley de la naturaleza ínsita ya en el alma. Así, en la predicación del Aquilense es impensable e inaceptable que con el actuar se retroceda al estado de pecado anterior a la revelación.

Desde esta perspectiva, en toda la producción de Cromacio, sea la homilética o la tratadística, la Sagrada Escritura representa un punto de referencia constante, sea porque a través de ella la fe recibe la justa señal para seguir, sea, sobre todo -al menos esto es lo que emerge de las palabras del Aquilense- porque el hombre en ella puede encontrar el espejo de sí mismo, de quién es él y de quién debería aspirar a ser (Auwers, 2011). El alejamiento de esta lex naturae provoca la muerte espiritual y eterna $y$, entonces, el triunfo de la terrena conversatio, que es mucho peor que la mera muerte corporal y temporal, que es, en cambio, preludio del triunfo en Cristo. Respecto a este punto, es interesante notar cómo este sermón en particular se aparta en su final de la norma del resto de la composición de Cromacio que, en gran parte, concluye con una doxología, una confesión de la alabanza en lo que concierne a la Divinidad. En este caso, en cambio, a la doxología se une la repetición didáctica: si por un lado se enaltece la alabanza, sin embargo, en su desarrollo se incluyen advertencias y consejos -en su mayoría prácticos- para los fieles, en línea con la intención de la composición en general. En efecto, la alabanza a Dios es en su conjunto la misma vita activa, concebida según la inspiración de la Escritura y proporcional al don de la gracia.

De acuerdo con este sermón de Cromacio, la vita activa, con la adhesión a la lex naturae, de la que el episodio del centurión Cornelio constituye el ejemplo más claro, signan una fuerte dicotomía entre un "nosotros" y un "ellos", que en la intención del Aquilense se traduce en una separación explícita entre quien es parte de la comunidad cristiana y quien se encuentra fuera de ella. En la semántica del Sermo, entonces, se genera una fuerte oposición entre los mundati, aquellos que viven su vida de manera cristiana, y los communes, quienes por elección o por contingencia deciden apartarse de la gracia y de la ley natural. De hecho, juega aquí una función fundamental el tercer aspecto de la experiencia obispal de Cromacio, aquel relativo a la relevancia política y social ínsita en el cargo obispal y especialmente sentida por el Aquilense.

Mediante el recurso a comportamientos socialmente aceptados -y conocidos por todos- el Obispo refuerza, de hecho, la unidad del grupo social, en oposición a quienes, por el contrario, no adhiriendo a tal lexnaturae se declaran abiertamente ajenos a la sociabilidad. En otra parte, específicamente, en Sermo II, el mismo Cromacio insiste en la fuerza de tal adhesión: el obispo es expresión de los dictámenes eclesiásticos y la sociabilidad, si quiere mantenerse tal, tiene la obligación de atenerse a este género de comportamientos establecidos (Noce, 2016: 96). Una actitud inadecuada y, en tal sentido, subversiva, comporta la exclusión de la comunidad. La identidad del grupo queda reforzada no tanto gracias a la repetición continua en el sermón o a los tratados doctrinales unitivos, sino más bien en virtud de la estigmatización de lo que es contrario al sentido común, aquello que, en este caso, representa una activitas contraria a la lex naturae (Noce, 2017a). 
El ejemplo del pasaje de los Hechos constituye en el discurso cromaciano una referencia identitaria totalmente consistente, así como en la tradición anterior a él (Beatrice, 2014: 454-456). La adhesión del centurión testimonia la facultad propia del hombre de mantenerse adherente a tal ley innata, de poder, de esta manera, ingresar a ser parte del grupo, independientemente de las diversas proveniencias o historias individuales. ${ }^{21}$ La misma exégesis que se practica, con la referencia a la variedad animal que descendió del cielo delante de Pedro, refuerza este sentido identitario, siempre de manera opositiva. Se llega a crear, primero, con el pasaje de la Escritura y luego, con Cromacio, una separación explícita: cronológicamente, entre un antes y un después, socialmente, entre un adentro y un afuera.

En este sentido, es interesante notar cómo en la homilética del Aquilense cada referencia al mundo animal encuentra su significado específico; los pájaros, las serpientes, los cuadrúpedos y las bestias mencionadas en el sermón, todos hacen referencia a una condición humana precristiana, anterior al ingreso en la iglesia de Cristo (Noce, 2017b). Desligados de lo socialmente aceptado, con un comportamiento no acorde, se vive un retorno a la ignorancia de lo divino, a la malignidad y a la injusticia, representados por las fieras mencionadas (Noce, 2017b: 162-164). Así, se produce un retorno en la era de la cristiandad a un estado precristiano, del ser mundatus al communis. Si la gracia es universal, el único rasgo que distingue a los aquilenses (y al hombre cristiano en general) del resto de su contexto contingente -dividido entre un paganismo formal todavía difuso y las presiones internas de la comunidad hebraica y externas de los invasores bárbaros (Noce, 2017a: 208-210)- es la adhesión formal a este género particular de vita activa, expresión de la vita superna comprendida sea de manera terrena, sea ultramundana.

\section{Estilos y fuentes del Sermo III}

Sostuvimos, pues, que la intención principal del Obispo es la máxima comprensión y la influencia que tal comprensión puede tener en los comportamientos ordinarios de sus oyentes. Como consecuencia, el estilo de la oración se conecta de manera analógica con el objetivo que el orador se propone. La escritura y la retórica del autor se revelan, en efecto, especialmente claras y directas, de modo tal que el auditorio no tenga posibilidad de malinterpretar o, incluso, de no comprender lo que es inherente a la Escritura. Del mismo modo, en el nivel del registro no se encuentran picos de elevación, sino que mantiene más o menos el mismo nivel durante todo el sermón.

Al mismo fin responde la casi extenuante repetición de algunos giros de palabras; generalmente se trata de proposiciones tomadas del texto de los Hechos, que el autor casi que intenta inculcar en las mentes de los oyentes. Se trata de expresiones breves y simples que retoman, de manera casi escolar, el concepto; constituyen pequeños extractos del mensaje evangélico para tener al alcance de la mano y no olvidar en el resto del recorrido. Por ello, la retórica se aparta fuertemente tanto de aquella clásica pagana, como también de aquella contemporánea a Cromacio: no encontramos la dramaticidad de un Rutilio Namaciano o el refinamiento de un Amiano Marcellino, ${ }^{22}$ sino un texto de composición escueta que pone el acento en el contenido más que en su forma. Pues esta última es seca, decidida y se concentra directamente en su finalidad para, así, evitar contraerse sobre sí misma. El tono es casi coloquial, de manera que permite al auditorio un aprendizaje más fluido. También es coloquial el lenguaje utilizado, con un latín que se aleja cada vez más de Cicerón y se acerca

21 Como demuestra el episodio siguiente en la exégesis cromaciana, referido a Pedro.

22 Sobre la retórica y la prosa del tiempo de Cromacio, véase Norden, 1898. 
poderosamente a Gregorio Magno. ${ }^{23}$ De esta manera, el léxico es popular, cercano a quien escucha; se pasan por alto términos percibidos como lejanos, dejando su lugar a un vulgarismo ya de largo uso literario, como la sustitución de edere por manducare. ${ }^{24}$ El modelo de tales elecciones estilísticas resulta ser, en última instancia, la misma Escritura Sagrada, accesible en sus formulaciones a la comprensión de la mayoría. $\mathrm{Al}$ perseguir los mismos fines, el Obispo elige no alejarse de ese modelo sino, por el contrario, hacer de él un uso extensivo.

Así, los Sermones no fueron realizados con la intención de circular como libro, sino que pueden ser considerados testimonios fieles de la voz del Obispo, aunque no es impensable una posible reelaboración. ${ }^{25}$ En este sentido, queda el hecho de que el rasgo característico del tercero de los sermones cromacianos tenga cierta simplicidad expositiva, que se explica en una sucesión de proposiciones breves expuestas con el léxico menos complicado posible. Por tanto, la forma asume, al allanarse, una relevancia notable, tanto en el nivel retórico como social. Si es cierto que la claridad expositiva vierte el contenido de una manera todavía más fuerte, con todo es también verdadero que el mensaje exegéticamente conseguido no podía no precisar un estilo de tal género: una comunidad acogedora -como el canasto que descendió a Pedroy abierta a todos -como en las intenciones de Cromacio- debe hacer que todos se incluyan primariamente en sus características fundamentales, algunas de las cuales expresamente se señalan en Sermo III. Del mismo modo, la búsqueda identitaria por medio de una vita activa común requiere una adhesión general y una consiguiente nivelación del medium expositivo. Por ello, se percibe desde esta uniformidad retórica cómo el auditorio debería, cuanto menos, ser un compuesto, formado por ciudadanos de varias extracciones sociales y de diverso nivel de instrucción.

Como señalé, la principal fuente del Obispo de Aquilea es la Sagrada Escritura, utilizada por Cromacio en varias versiones, pero, sobre todo, en la Vetus Latina (Auwers, 2011). Efectivamente, el uso del aparato de las Escrituras es determinante en todo el despliegue del sermón, cada palabra del autor tiene conexión con un pasaje del Nuevo Testamento o parte de él: el episodio que es objeto de exégesis está casi completamente citado en la oración. Sin embargo, también se presentan numerosas referencias a otros pasajes de la Escritura que brindan fundamento ontológico al texto. No obstante, entre los autores tomados como inspiración para el sermón, en un primer plano corresponde presentar al alejandrino Orígenes, ${ }^{26}$ que Cromacio debía conocer en su traducción latina por medio de su amigo y conciudadano Rufino. ${ }^{27}$ Las referencias a Orígenes son decididamente las más numerosas en este sermón, indicador de la tendencia del Aquilense de darle abundante uso. Del alejandrino, Cromacio recupera no solo la letra, sino, sobre todo, la ratio exegetica y sus debidas conclusiones. Esto es evidente en el sermón en cuestión, mientras que en III.5 y en III.8 Cromacio reutiliza el origeniano In Leu. VIII.4, no en forma de citación directa y literal, sino como fuente interpretativa. En términos más generales, podemos luego notar cómo el autor cita y obtiene inspiración, en primer lugar, de autores conocidos por vía directa: Orígenes, como fue señalado

23 Numerosos son los ejemplos al interior del texto de un latín vulgar, como desplazamientos de significado, grafías erradas y construcciones cuasi romances.

24 Tanto en este como en otros casos, el ejemplo de la Vetus Latina debe haber jugado un rol fundamental. Cf. Mohrmann, 1961.

25 No es improbable que se trata de revisiones de textos contenidos en los archivos de la diócesis, sea por la obra de la secretaría patriarcal, sea del mismo Cromacio. Cf. Cerno, 2015: 9-10.

$26 \mathrm{El}$ ascenso a la terraza como símbolo de búsqueda de bienes superiores, y la iglesia pura siendo simbolizada con la sábana blanca son notas tomadas de Orígenes.

27 Cromacio declara abiertamente que realiza la exégesis a la manera de Orígenes, al utilizar la alegoría, a diferencia de su contemporáneo Ambrosio. Para la relación entre el obispo de Aquilea y las traducciones latinas de Orígenes y la obra de Rufino, véase Corsato, 2008. 
a través del latín de Rufino, pero también Ambrosio, ${ }^{28}$ su corresponsal, y los casi contemporáneos Agustín de Hipona ${ }^{29}$ y Máximo de Turín. ${ }^{30}$

De esta manera, la cultura literaria de Cromacio -también y sobre todo cristianano se muestra demasiado profunda, sino más bien parece hacer uso de lo mínimo indispensable para su propósito. El recurso a ilustres predecesores o contemporáneos muestra la necesidad del autor de insertarse en una tradición: la voz de las auctoritates se convierte en fuente de primaria importancia con el fin de garantizar corrección formal y ortodoxia a la doctrina expuesta. Esta fuerte voluntad de inserción en un trasfondo común, así como se refleja en el Sermo en cuestión, y en un contexto doctrinal común a otras personalidades de la Italia septentrional de su tiempo, se alinea en buen modo con la finalidad de la totalidad de la oración. En un contexto de fuertes presiones externas y de grupos heterodoxos que desde el interior minaban la estabilidad comunitaria (Noce, 2011; 2017b), resulta un intento primario del obispo, ciertamente, la expresión de puntos comunes. En efecto, la búsqueda identitaria que se mencionó más arriba condiciona en cierto modo también la elección de las fuentes, llevando a Cromacio -influenciado obviamente también por la propia formación y por su propia competencia- a seleccionar, en su mayoría, referencias contemporáneas, en la voluntad de construir en el escuchar un sedimento de doctrina y un impulso a la vita activa compartida también por otras comunidades.

La creación de este conjunto de conocimientos para uso de la fe responde, en última instancia, a la necesidad del obispo de poner un freno a las siempre más insistentes presiones heréticas (McEachnie, 2014), sobre todo arrianas, siempre fuertes durante la producción del Aquilense y culminada, con toda probabilidad, en su presencia en el concilio de Dióspolis del 415 (Beatrice, 2014: 449-452). Con todo, al mismo tiempo es necesario poner de manifiesto cómo la cita es casi siempre literal y abierta, aunque no declarada; la misma exégesis de Cromacio depende de modelos precedentes, montados por él nuevamente en otro contexto, pecando, no obstante, de muy poca originalidad. Así, independientemente de la selección limitada de autores, hay que reconocer que en cada caso los puntos de apoyo que utiliza son numerosos, demostrando una notable capacidad de análisis y síntesis.

\section{Conclusiones}

A la luz de lo que fue expuesto, resultan evidentes los objetivos puramente didácticos, casi pedagógicos, del tercero de los Sermones cromacianos. El ímpetu pastoral tiene como finalidad conducir a los fieles al recto camino, mientras la exégesis, profunda pero casi atrofiada en los limitados modelos utilizados, tiende a aportar las bases fundamentales de una correcta doctrina cristiana. Con todo, lo que emerge de manera más evidente es el valor atribuido por el Obispo a la vita activa, como medio supremo

28 El modelo ambrosiano es claro en Sermo III.1: "Indictum est legitimum ieiunum nuper, pauci ieiunaverunt". En In. Ps. CXVIII.8.48 el Obispo de Milán había escrito: "Indictum est ieiunum, cave ne neglegas". Además, es también claro el modelo ambrosiano en Sermo III.6 por la estructura y el concepto expresado; de hecho, retoma el mismo pasaje en Ambrosio, De Sp. Sanct. II.10.109: "eramus ergo ferae, ecc...".

29 De Agustín de Hipona se toma como inspiración un sermón homólogo en este punto del Obispo de Aquilea. En Sermo III.2 podemos leer: "sed forte aliqui dicant stomaci causa ieiunare non possint. Numquid stomaci causa est eleemosynam non facere?". La referencia al Sermo CCX.12 agustiniano es clara: "Potest quisque dicere: 'Ne stomachus doleat, ieiunare non possum'. Potest etiam dicere: 'Volo dare pauperi, sed unde, non habeo aut tantum habeo, ut timeam egere, si dedero'”.

30 Máximo de Turín opera como modelo para la sección relativa a la visión de Pedro, sobre el análisis de su ascenso al plano superior y de la sensación de hambre en Sermo III.6. En este caso, la citación no es literal, sino que se limita a ser conceptual, retomando el método exegético y las conclusiones del turinense, que escribe en Sermo II.2: "Post orationem ergo esurit Petrus. Mirandum cur sanctum virum post orationem fames sequatur, cum soleat fames oratione depelli et esuriens anima nonnisi obsecrationibus saginari. Sed puto Petrum post orationem non cibum esurisse hominum, sed salutem; nec inedia vexatum esse corporis, sed inopia credentium laborasse". En esta sección, de manera secundaria, Cromacio de Aquilea emplea también la exégesis de Hilario de Poitiers, específicamente In Mt. 12.2. El modelo de Hlario está siempre presente, pero también siempre en un segundo nivel en relación con otros usos que son más claros y directos. 
-junto con la gracia- para alcanzar la salvación individual. Como el episodio del centurión Cornelio parece demostrar, para Cromacio la acción debe adherir a la lex naturae divina ínsita en alma humana por lo que, justamente en virtud de esto, cada desviación de ella es prácticamente impensable.

En el impulso hacia una adhesión general a este género de comportamiento y en relación con esta norma innata, emerge claramente la voluntad del orador de expresar y hacer evidente los rasgos constitutivos de la identidad comunitaria. Al estigmatizar a aquel que se aparte de esto socialmente aceptado, Cromacio construye en su exégesis lo que puede ser la identidad del grupo oponiéndola a lo que es externo a ella. Las contingencias históricas, entre la fuerte presencia bárbara en la Italia septentrional y las siempre más insistentes presiones arrianas, jugaron seguramente su parte en la institución de tal voluntad en la obra pastoral del Aquilense. De este modo, el Sermo III se configura como expresión del intento del Obispo de consolidar su auditorio en torno a un bagaje doctrinal -extremadamente escueto- y a un comportamiento comunitario, con el propósito de frenar sus insistentes arrebatos centrípetos.

A este mismo fin responden el estilo y las fuentes utilizadas por el Aquilense: el uso de un lenguaje llano, siempre ligado al antecedente escritural, y el llamado a relacionarse, en su mayoría, con contemporáneos y aquellos cercanos geográficamente hace, en un cierto sentido, que el autor pueda dirigir su propia voz a la mayor cantidad posible de oyentes, e introduce a Cromacio y su auditorio dentro de una comunidad más vasta que la simple diócesis de Aquilea. Una comunidad que, en el caso del Sermo III, se reconoce en un valor común atribuido a la vita activa. Así, un punto central es esta teología del mérito, conectada de manera vinculante tanto a la acción como a la gracia, que en cierto modo anticipa y preanuncia las grandes teorizaciones de Agustín y del Concilio de Éfeso del 431 contra el pelagianismo. 


\section{Q Bibliografía}

\section{Fuentes}

»Augustinus (2015). Sermones selecti. Ed. Weidmann, C. Berlín: De Gruyter. (CSEL 101).

»Ambrosius (1964). De spiritu sancto libri tres. Ed. Faller, O. Viena: De Gruyter: (CSEL 79).

»Ambrosius (1913). Expositio Psalmi CXVIII. Ed. Petschenig, M. Viena: De Gruyter (CSEL 62)

» Chromatius Aquilensis (1974). Opera. Eds. Étaix, R. y Lemarié, J. Turnhout: Brepols. (CCSL 9A).

»Chromatius Aquilensis (1977). Spicilegium ad Chromatii Aquileiensis opera. Eds. Lemarié, J. y Étaix, R. Turnhout: Brepols. (CCSL 9A Supplementum).

" Maximus Taurinensis (1961). Sermonum collectio antiqua, nonnullis sermonibus extravagantibus adiectis. Ed. Mutzenbecher, A. Turnhout: Brepols. (CCSL 23).

\section{Bibliografía complementaria}

»Auwers, J. M. (2011). "Chromace d'Aquilée et le texte biblique". En: Beatrice, P. F. y Persic A. (eds.). Chromatius of Aquileia and his age. Proceedings of the International Conference held in Aquileia, 22-24 May 2008. Turnhout: Brepols.

» Banterle, G. y Lemarié, J. (1989). Chromatii Aquileiensis sermones. Milán-Roma: Città Nuova Editrice.

» Beatrice, P. F. (2014). "Chromatius and Jovinus at the Synod of Diospolis: a Prosopographical Inquiry", Journal of Early Christian Studies 22.3, 437-464.

" Bratoz, R. (1999). Il cristianesimo aquileiese prima di Costantino, Fra Aquileia e Poetovio. Udine: Ist. Pio Paschini.

»Cerno, M. (2015). "I sermoni di Cromazio, vescovo di Aquileia (388-408). Nuove acquisizioni dalla ricognizione della tradizione manoscritta", Vetera Christianorum $52,7-27$.

"Cerno, M. (2019). I sermoni. Cromazio di Aquileia. Nuova edizione con traduzione a fronte di Marianna Cerno. Roma: Istituto Storico Italiano per il Medioevo.

" Corgnali, D. (1979). Il mistero pasquale in Cromazio di Aquileia. Udine: La Nuova Base.

»Corsato, C. (2011). "Cromazio interprete della Scrittura nei Sermones". En: Beatrice, P. F. y Persic, A. (eds.). Chromatius of Aquileia and his age. Proceedings of the International Conference held in Aquileia, 22-24 May 2008. Turnhout: Brepols.

"Crouzel, H. (1964). "La distinction de la 'typologie' et de l"allegorie'", Bulletin de Littérature Ecclésiastique 65, 161-174.

»Étaix, R. (1981). "Un 'Tractatus in Matheum' inédit de Saint Chromace d'Aquilée", Revue Bénédectine 91, 225-230. 
» Lemarié, J. (1969-1971). Chromatii Aquileiensis Sermones. Paris: Les Editions du Cerf. (SCh 164).

» Lemarié, J. (1969). “Le témoignage du martyre d'après les sermons de Chromace d'Aquilée", Rivista di Storia e Letteratura Religiosa 5, 3-12.

" Maritano, M. y Dal Covolo E. (2003). Omelie sul Levitico. Roma: LAS.

» McEachnie, R. (2017). Chromatius of Aquileia ad the making of a Christian City. Londres-Nueva York: Routledge.

» Mohrmann, C. (1961). "Praedicare, Tractare, Sermo". En: Mohrmann, C. (ed.), Études sur le latin des chrétiens, II. Roma: Edizioni di Storia e Letteratura.

» Noce, E. (2011). "Herejía e identidad cristiana en el corpus del Cromacio de Aquileya", Anales de Historia Antigua, Medieval y Moderna 44, 171-200.

»Noce, E. (2016). "Supervivencias paganas en la antiguedad tardía: el testimonio del Sermo II de Cromacio de Aquileya", Aquileia Nostra 87, 81-100.

» Noce, E. (2017a). "Barbarians and Christians Identity in the Corpus of Chromatius of Aquileia", Athenaeum 150.1, 207-229.

" Noce, E. (2017b). "El recurso a los animales en la obra de Cromacio de Aquileya", Biblioteca Augustiniana 8.1, 155-180.

" Norden E. (1898). Die antike Kunstprosa. Leipzig: Teubner.

» Simonetti, M. (2012). Lettera e/o Allegoria. Roma: Ist. Patristico Augustinianum.

»Sotinel, C. (2005). Identité civique et christianisme. Aquilée di III eau VIe siècle. Roma: École française de Rome.

"Sotinel, C. (2011). "L'évêque chrétien devant la diversité religieuse de la cité: Chromace et Aquilée". En: Beatrice P. F. y Persic A. (eds.), Chromatius of Aquileia and his age. Proceedings of the International Conference held in Aquileia, 22-24 May 2008. Turnhout: Brepols.

» Todde, M. (1982). Cromazio di Aquileia, Sermoni Liturgici. Roma: Paoline.

» Trettel, G. (1974). “Figura e Veritas nell'opera oratoria di san Cromazio, Vescovo di Aquileia", La Scuola Cattolica 102, 3-26.

» Trettel, G. (1974). "Terminologia esegetica nei sermoni di san Cromazio di Aquileia", Revue des Études Augustiniennes 20, 55-81.

» Trettel, G. (1981a). "Tipologia figurale in san Cromazio, Vescovo di Aquileia", Memorie storiche Forogiuliesi 59, 25-79.

» Trettel, G. (1981b). “Cristologia cromaziana (Appunti)”, Ricerche Religiose del Friuli e dell'stria 1, 3-86.

» Trettel, G. (1983). "L'esperienza dello Spirito Santo nella vita della Chiesa e dei cristiani in Cromazio di Aquileia". In: Felici, S. (ed.). Spirito Santo e catechesi patristica. Roma: LAS, 93-132.

» Trettel, G. (1984). Cromazio di Aquileia, Commento al vangelo di Matteo. Roma: Città Nuova Editrice.

» Truzzi, C. (1981). Zeno, Gaudenzio e Cromazio. Brescia: Paideia. 